\title{
OPTIMIZATION OF THE LEVEL OF INGREDIENTS FOR FUNCTIONAL DAIRY BEVERAGE USING RESPONSE SURFACE METHODOLOGY (RSM)
}

\author{
P. Shukla*, U. Bajwa and S. Sharma \\ Department of Food Science and Technology, Punjab Agricultural University, Ludhiana, 141004 Punjab. India
}

(Received: 1 February 2013, accepted: 9 May 2013)

\begin{abstract}
The present investigation was undertaken to optimize the level of ingredients (milk fat, sugar, and mango pulp) for functional dairy beverage using Response Surface Methodology. Central Composite Rotatable Design with milk fat (\%), sugar (\%), and mango pulp (var. Chaunsa, \%) as independent variables produced 20 different combinations that were used to investigate the effect on viscosity (cP), antioxidant activity, and overall acceptability. The response surface three dimensional graphs were plotted as a function of two variables to show the effect of level of ingredients on physico-chemical and sensory properties of the beverage. Significant correlation models were established with the coefficient of correlation $\left(\mathrm{R}^{2}\right)$ greater than 0.8 . An optimization of process variables was attempted for maximum antioxidant activity and overall acceptability. ANOVA tables revealed that increase in fat and sugar levels lowered the antioxidant activity, while enhancement of mango pulp significantly increased both antioxidant activity and overall acceptability of the beverage. The optimized levels of ingredients were $0.5 \%$ milk fat, $6.0 \%$ sugar and $30 \%$ mango pulp.
\end{abstract}

Keywords: antioxidants, dairy, beverage, mango, response surface methodology (RSM)

Consumers' approach to healthy and functional foods has been changed during the last decade. Boosting the health of consumers through consumption of healthy food has become more important than simply enhancing the life span. Functional dairy beverages are a key segment in the rapidly growing functional food market and are indeed a realistic approach to consumer's expectations for boosting the immune system, relieving stress, improving intestinal health, increasing vitality and stamina, controlling cholesterol and body weight, and fighting against degenerative diseases (OzER \& KIRMACI, 2009). Modifications of dairy products include replacements or reductions of fat, cholesterol, sodium, and calories and addition of beneficial components, such as calcium, fruit pulp, fruit juice, etc. The prevention of potential age-related health issues, such as coronary diseases, vitality loss, and bone weakness, are the areas of recent interest (SMIT, 2003).

In the last decade, much attention has been focused on naturally derived substances that provide antioxidant effects to human beings (MAKHLOuF et al., 2011). Fruit and vegetables are good sources of natural antioxidants, such as carotenoids, vitamins, phenols, flavonoids, dietary glutathione, and endogenous metabolites. Dairy based beverage supplemented with natural oxygen-scavenging ingredient has the capacity to overcome the consequences of reactive oxygen species (WANG et al., 2009).

Response surface methodology (RSM) has been successfully used to model and optimize biochemical and biotechnological processes related to food systems (LiYANA-PATHIRANA \& SHAHIDI, 2005). RSM enables evaluation of the effects of several process variables and their

\footnotetext{
* To whom correspondence should be addressed.

Phone: +919872163989; fax: 91-161-2410293; e-mail: preeti_cft@rediffmail.com
} 
interactions on response variables (OzDEMIR et al., 2008). The versatility of the antioxidant defence system implies that it is capable of taking advantage of diverse antioxidants provided by the diet, as well as use of a particular antioxidant nutrient (JACOB, 1995). Therefore, the investigation was proposed to study the role of antioxidative components in fruit (mango) and other ingredients in fruit based dairy beverages and assess the physicochemical and sensory properties.

\subsection{Materials}

\section{Materials and methods}

Whole milk was procured from College of Dairy Science and Technology, Guru Angad Dev Veterinary and Animal Sciences University (GADVASU). Milk was separated at $35{ }^{\circ} \mathrm{C}$ in a cream separator (Elecrem, France) to obtain skimmed milk. It was pasteurized and blended with the pasteurized standardized milk (4.5 percent fat) to achieve the desired fat levels. Mango (var. Chaunsa) and sugar were procured from the local market of Ludhiana, Punjab. DPPH was procured from Sigma Aldrich, USA. All the chemicals used were AR grade. Mango pulp of fine consistency was prepared and pasteurized at $90{ }^{\circ} \mathrm{C}$ for $2 \mathrm{~min}$ (SHARMA, 1999). It was hot-filled in glass bottles, sealed, and refrigerated for further use (Fig. 1).

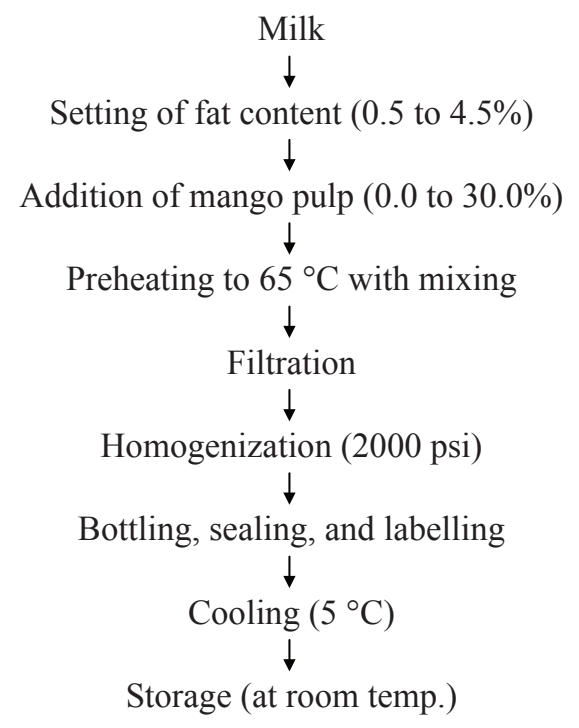

Fig 1. Flow diagram of preparation of mango flavoured milk drinks

\subsection{Experimental design and statistical analysis for optimization of ingredients}

Response surface methodology (RSM) consists of a group of empirical techniques for the evaluation of relation existing between a cluster of controlled experimental factors and the measured responses, according to one or more selected variables under investigation that are necessary for achieving a more realistic model. Three variables were selected to find the optimized level of ingredients for functional dairy beverage using Central Composite Rotatable Design (CCRD). The independent variables studied were milk fat ( $\%$, v/v), sugar 
content $(\%, \mathrm{w} / \mathrm{v})$ and level of mango pulp $(\%, \mathrm{w} / \mathrm{v})$, while response variables were viscosity $(\mathrm{cP})$, antioxidant activity (\% inhibition of DPPH), and overall acceptability. The ranges of the experimental variables used in the study and responses obtained are given in Table 1.

The central values (zero level) chosen for experiment design were milk fat $2.5 \%(\mathrm{v} / \mathrm{v})$, sugar $3.0 \%(\mathrm{w} / \mathrm{v})$, and mango pulp $15.0 \%(\mathrm{w} / \mathrm{v})$ in developing the regression equation.

Table 1. The experimental design with responses for the optimization of variables using central composite rotatable design

\begin{tabular}{|c|c|c|c|c|c|c|c|}
\hline $\begin{array}{l}\mathrm{Std}^{\mathrm{a}} \\
\text { order }\end{array}$ & $\begin{array}{l}\text { Run }{ }^{\mathrm{b}} \\
\text { order }\end{array}$ & $\begin{array}{l}\text { Factor } 1 \\
\text { A: fat } \%\end{array}$ & $\begin{array}{c}\text { Factor } 2 \\
\text { B: sugar\% }\end{array}$ & $\begin{array}{l}\text { Factor } 3 \\
\text { C: pulp\% }\end{array}$ & Response1 & Response2 & Response3 \\
\hline 18 & 1 & 2.50 & 3.00 & 15.00 & 5.067 & 36 & 7.37 \\
\hline 14 & 2 & 2.50 & 3.00 & 40.23 & 28.490 & 36 & 7.9 \\
\hline 10 & 3 & 5.86 & 3.00 & 15.00 & 13.809 & 7.24 & 7.37 \\
\hline 12 & 4 & 2.50 & 8.05 & 15.00 & 4.605 & 28 & 8.01 \\
\hline 17 & 5 & 2.50 & 3.00 & 15.00 & 5.067 & 36 & 7.37 \\
\hline 2 & 6 & 4.50 & 0.00 & 0.00 & 1.756 & 42.02 & 7.5 \\
\hline 5 & 7 & 0.50 & 0.00 & 30.00 & 7.348 & 33.33 & 7.33 \\
\hline 7 & 8 & 0.50 & 6.00 & 30.00 & 4.598 & 58.8 & 8.54 \\
\hline 20 & 9 & 2.50 & 3.00 & 15.00 & 5.067 & 36 & 7.37 \\
\hline 19 & 10 & 2.50 & 3.00 & 15.00 & 5.067 & 36 & 7.37 \\
\hline 16 & 11 & 2.50 & 3.00 & 15.00 & 5.067 & 36 & 7.37 \\
\hline 11 & 12 & 2.50 & -2.05 & 15.00 & 5.533 & 33.33 & 7.16 \\
\hline 1 & 13 & 0.50 & 0.00 & 0.00 & 1.557 & 50.28 & 6.73 \\
\hline 3 & 14 & 0.50 & 6.00 & 0.00 & 1.343 & 43.18 & 6.92 \\
\hline 13 & 15 & 2.50 & 3.00 & -10.23 & 4.183 & 25.33 & 6.89 \\
\hline 8 & 16 & 4.50 & 6.00 & 30.00 & 7.350 & 39.13 & 8.195 \\
\hline 15 & 17 & 2.50 & 3.00 & 15.00 & 5.067 & 36 & 7.37 \\
\hline 9 & 18 & -0.86 & 3.00 & 15.00 & 3.681 & 51.7 & 7.3 \\
\hline 6 & 19 & 4.50 & 0.00 & 30.00 & 18.449 & 31.88 & 7.93 \\
\hline 4 & 20 & 4.50 & 6.00 & 0.00 & 4.533 & 18.84 & 7.68 \\
\hline
\end{tabular}

${ }^{\mathrm{a}}$ Randomized ; ${ }^{\mathrm{b}}$ Non randomized

Response1: viscosity (cp); Response2: antioxidant activity (\% inhibition of DPPH); Response3: overall acceptability score

\subsection{Selection of relevant variables and experimental ranges}

The initial step was selecting the experimental ranges for the independent variables. The optimization of milk fat is important as low fat milk drinks lack the particular mouth feel provided by fat, while high fat contents lead to high calorie intake. MitTAL and BAJWA (2012), using empirical method, evaluated the effect of levels of milk fat $(0.5-1 \%)$, sugar $(0-6 \%)$, and mango pulp (0-30\% var. Dusehri) on physico-chemical and sensory characteristics. For the present study, the CCRD was chosen to design a series of experiments and provide statistical and graphical data to determine the relationship between the responses (viscosity, 
antioxidant activity, and overall acceptability) and the three independent variables, i.e. milk fat, sugar, and mango pulp (var. Chaunsa), with the specific ranges (Table 1).

\subsection{Analyses of the response variables}

1.4.1. Viscosity. Viscosity was measured with Brookfield viscometer (Model LVT) at $20^{\circ} \mathrm{C}$ using spindle no. 2. The spindle was inserted and adjusted to the marked level in the sample container and viscosity was measured as dial reading at a speed of 12 r.p.m. after 5 rotations for each sample. The viscosity was calculated using the following formula:

$$
\begin{gathered}
\text { Viscosity }(\mathrm{cP})=\text { Dial reading } \times \text { factor* } \\
* \text { Factor for spindle } 2=25 \text { (at speed } 12 \text { r.p.m.) }
\end{gathered}
$$

1.4.2. Antioxidant activity. Antioxidant activity was estimated using standard procedure of DPPH (2,2-diphenyl-1-picrylhydrazyl) assay (TEPE et al., 2006). A volume of $6.0 \mathrm{ml}$ of DPPH solution $(0.2 \mathrm{mM}$ in $80 \%$ methanol) was mixed with $2.0 \mathrm{ml}$ of each sample. The samples were incubated for $30 \mathrm{~min}$ in dark at room temperature $\left(25 \pm 2{ }^{\circ} \mathrm{C}\right)$. The absorbance (A) was measured at $518 \mathrm{~nm}$ by using Spectronic-20 (Bausch and Lomb, USA) spectrophotometer. The percentage of the radical scavenging activity was calculated as percentage inhibition of DPPH radicals using the following equation:

$$
\% \text { inhibition of DPPH }=\left[\mathrm{A}_{\text {control }}-\mathrm{A}_{\text {sample }}\right] / \mathrm{A}_{\text {control }} \times 100
$$

$2.0 \mathrm{ml}$ methanol (80\%) plus $6.0 \mathrm{ml}$ distilled water was used as a blank. For the control, DPPH solution replaced distilled water.

1.4.3. Overall acceptability. All milk drink samples were evaluated for appearance/ colour, flavour, body and mouth feel, and overall acceptability by a semi-trained panel of eight judges from the department using a nine point hedonic scale with scores ranging from liked extremely (9) to disliked extremely (1) (MeILGAARD et al., 1999). The overall quality scores were calculated by taking the mean of all three attributes.

\subsection{Optimization and validation of the model}

'Design expert-8.0.7.1' software was used for regression and graphical analysis of the data. The optimum values of the selected variables were obtained by solving the regression equation and also by analyzing the response surface three-dimensional plots.

\section{Results and discussion}

\subsection{Fitting the models}

The experimental values for responses (viscosity, antioxidant activity, and overall acceptability) ranged from 1.343 to $28.49 \mathrm{cP}, 7.245$ to $58.80 \%$ and 6.73 to 8.54 , respectively, under different combination of levels of milk fat, sugar, and mango pulp. The fitness and adequacy of the model was judged by the coefficient of determination $\mathrm{R}^{2}$. The coefficient of determination $\left(\mathrm{R}^{2}\right)$ for viscosity, antioxidant activity, and overall acceptability were 0.8336 , 0.8887 , and 0.9400 , respectively for the regressed model, suggesting a good fit. 
The significance of each coefficient was determined using $F$-test and P-value. The $F$-values for all response models were greater than the tabulated $F$-value indicating the adequacy of the models to predict various responses at different levels of ingredients.

\subsection{Analysis of response surface}

2.2.1. Effect of levels of fat, sugar, and pulp on the viscosity of mango based dairy beverage. Fig. 1 shows that the variation in both fat and pulp had a pronounced effect on the viscosity (cP) of the beverage. It reveals that on increasing the fat content a significant increase in viscosity is observed. Similar findings were recorded by PHILLIPS and co-workers (1995). Augmented sugar levels have a non-significant negative effect on viscosity as it has the dilution effect on the beverage. On keeping the milk fat constant, increment in sugar and pulp enhanced the overall viscosity of the beverage. All the ingredients have a significant interactive effect on the viscosity of the beverage. The data (Table 2) indicate that the model can be better fitted at linear level $(\mathrm{P}<0.1)$ and non-significant at interactive level $(\mathrm{P}<0.1)$.

The Model $F$-value of 5.57 implies that the model is significant. Values of " $\mathrm{P}>F$ " less than 0.0500 indicate model terms are significant.

Final equation in terms of coded factors:

Viscosity $=5.21+2.51 \times \mathrm{A}-0.94 \times \mathrm{B}+5.08 \times \mathrm{C}-0.67 \times \mathrm{A} \times \mathrm{B}+1.31 \times \mathrm{A} \times \mathrm{C}-2.05 \times \mathrm{B} \times \mathrm{C}$ where, A: fat, B: sugar, C: pulp.

Table 2. ANOVA for response surface quadratic model of viscosity

\begin{tabular}{lccccc}
\hline Factors & $\begin{array}{c}\text { Coefficient } \\
\text { estimate }\end{array}$ & $\begin{array}{c}\text { Sum of } \\
\text { squares }\end{array}$ & DF & $F$-value & Prob $>F$ \\
\hline Intercept of model & 5.21 & 658.12 & 9 & 5.57 & 0.0065 \\
A: fat & 2.51 & 86.02 & 1 & 6.55 & 0.0284 \\
B: sugar & -0.94 & 12.08 & 1 & 0.92 & 0.3601 \\
C: pulp & 5.08 & 353.03 & 1 & 26.88 & 0.0004 \\
AB (fat $\times$ sugar) & -0.67 & 3.59 & 1 & 0.27 & 0.6126 \\
AC (fat $\times$ pulp) & 1.31 & 13.69 & 1 & 1.04 & 0.3314 \\
BC (sugar $\times$ pulp) & -2.05 & 33.67 & 1 & 2.56 & 0.1404 \\
$\mathrm{R}^{2}$ & 0.8336 & & & & \\
\hline
\end{tabular}

2.2.2. Effect of levels of fat, sugar, and pulp on the antioxidant activity of mango based dairy beverage. The three dimensional plot for antioxidant activity of dairy based beverage as the response in function of two factors and keeping the other fixed at middle level is shown in Fig. 2. The graph indicates that on increasing the fat percentage, the antioxidant activity decreased at a constant level of mango pulp, this may be due to the hindrance effect of fat globules on mango pulp, which inhibits the antioxidative components to show the inhibition of DPPH radicals. Figure 2 explains that the increase in pulp level increased the antioxidant activity at constant sugar content, because of the higher concentration of antioxidants in pulp. Higher sugar content at constant fat level lead to a decrease in the antioxidant activity due to the dilution effect on mango components. In reference to Table 3, the Model $F$-value of 4.15 implies that the model is significant. Values of " $\mathrm{P}>F$ " less than 0.0500 indicate model terms are significant.

Final equation in terms of coded factors:

Antioxidant activity $=35.61-10.73 \times \mathrm{A}-1.80 \times \mathrm{B}+3.28 \times \mathrm{C}-2.03 \times \mathrm{A} \times \mathrm{B}-0.83 \times \mathrm{A} \times \mathrm{C}+5.61 \times \mathrm{B} \times \mathrm{C}$ where, A:fat, B: sugar, C: pulp. 
a

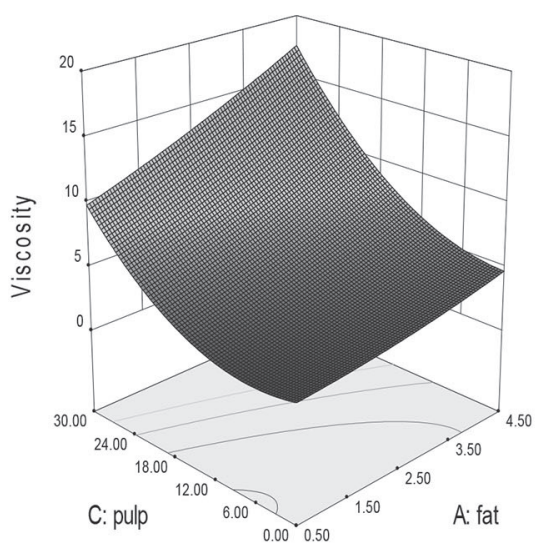

b

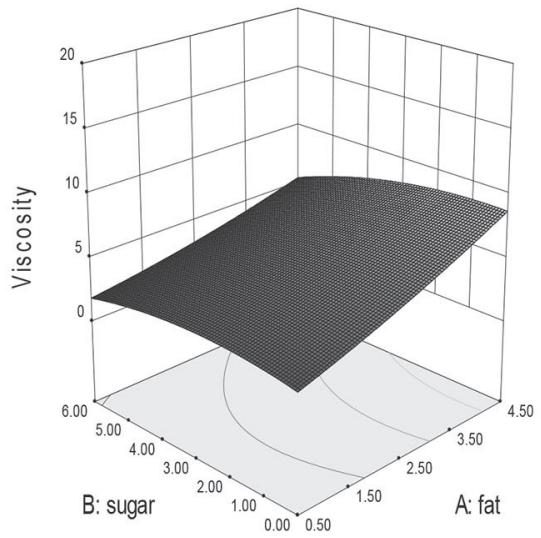

C

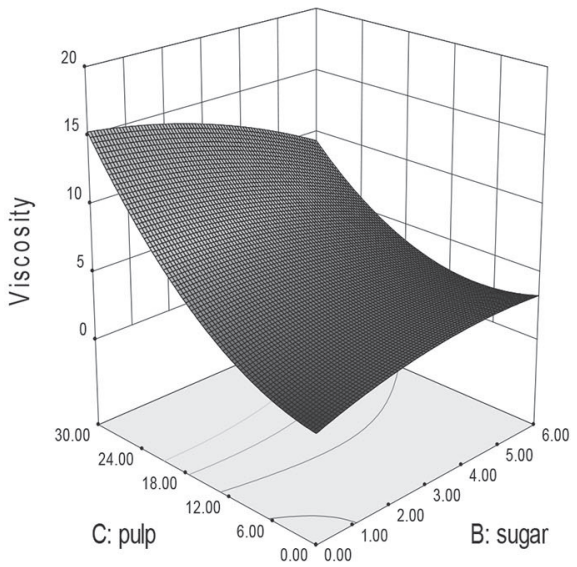

Fig 2. Three dimensional plot for viscosity:

a: $\mathrm{X} 1=\mathrm{A}$ : fat; $\mathrm{X} 2=\mathrm{C}$ : pulp; Actual factor $\mathrm{B}$ : sugar $=3.0$

b: $\mathrm{X} 1=\mathrm{A}$ : fat; $\mathrm{X} 2=\mathrm{B}$ : sugar; Actual factor $\mathrm{C}$ : $\mathrm{pulp}=15.0$;

c: $\mathrm{X} 1=\mathrm{B}$ : sugar; $\mathrm{X} 2=\mathrm{C}$ : pulp; Actual factor $\mathrm{A}$ : fat $=2.50$

Table 3. ANOVA for response surface quadratic model of antioxidant activity

\begin{tabular}{lcccrc}
\hline Factors & $\begin{array}{c}\text { Coefficient } \\
\text { estimate }\end{array}$ & $\begin{array}{c}\text { Sum of } \\
\text { squares }\end{array}$ & DF & $F$-value & Prob $>F$ \\
\hline Intercept of model & 35.61 & 2066.72 & 9 & 4.15 & 0.0184 \\
A: fat & -10.73 & 1573.31 & 1 & 28.41 & 0.0003 \\
B: sugar & -1.80 & 44.36 & 1 & 0.80 & 0.3918 \\
C: pulp & 3.28 & 147.32 & 1 & 2.66 & 0.1339 \\
AB (fat $\times$ sugar) & -2.03 & 32.85 & 1 & 0.59 & 0.4590 \\
AC (fat $\times$ pulp) & -0.83 & 5.46 & 1 & 0.099 & 0.7599 \\
BC (sugar $\times$ pulp) & 5.61 & 252.11 & 1 & 4.55 & 0.0587 \\
$\mathrm{R}^{2}$ & 0.8887 & & & & \\
\hline
\end{tabular}


2.2.3. Effect of levels of fat, sugar, and pulp on the overall acceptability of mango based dairy beverage. The three dimensional plot for antioxidant activity of dairy based beverage as the response in function of two factors and keeping the other fixed at middle level is shown in Fig. 3. Figure 3 shows that on keeping the sugar level constant, an increase in the fat level increases the overall acceptability, as fat improves the mouth feel of the beverage. While keeping the fat constant, an increase in the sugar level enhanced the overall acceptability by imparting the optimal sweetness to the beverage. Table 4 shows that an increase in the level of mango pulp significantly raised the overall acceptability scores as the pulp provides better texture and mouth feel to the beverage.

The Model F-value of 17.40 implies that the model is significant. Values of "P $>F$ " less than 0.0500 indicate model terms are significant.

Final equation in terms of coded factors:

Overall acceptability $=7.37+0.18 \times \mathrm{A}+0.24 \times \mathrm{B}+0.36 \times \mathrm{C}-0.12 \times \mathrm{A} \times \mathrm{B}-0.15 \times \mathrm{A} \times \mathrm{C}+0.13 \times \mathrm{B} \times \mathrm{C}$ where, A: fat, B: sugar, C: pulp.

Table 4. ANOVA for response surface quadratic model of overall acceptability score

\begin{tabular}{lccccc}
\hline Factors & $\begin{array}{c}\text { Coefficient } \\
\text { estimate }\end{array}$ & $\begin{array}{c}\text { Sum of } \\
\text { squares }\end{array}$ & DF & $F$-value & $\mathrm{P}>F$ \\
\hline Intercept of model & 7.37 & 3.62 & 9 & 17.40 & 0.0001 \\
A: fat & 0.18 & 0.45 & 1 & 19.53 & 0.0013 \\
B: sugar & 0.24 & 0.76 & 1 & 33.00 & 0.0002 \\
C: pulp & 0.36 & 1.76 & 1 & 75.92 & 0.0001 \\
AB (fat $\times$ sugar) & -0.12 & 0.12 & 1 & 5.40 & 0.0425 \\
AC (fat $\times$ pulp) & -0.15 & 0.19 & 1 & 8.30 & 0.0163 \\
BC (sugar $\times$ pulp) & 0.13 & 0.14 & 1 & 6.07 & 0.0335 \\
$\mathrm{R}^{2}$ & 0.9400 & & & & \\
\hline
\end{tabular}

\section{Conclusion}

Response surface methodology was successfully used to determine the level of ingredients that yielded the mango based functional beverage with maximum antioxidant activity along with the highest overall acceptability, keeping the viscosity in range. The second-order polynomial model gave a satisfactory description of the experimental data. The study revealed that increase in fat and sugar content had negative effect on antioxidant activity, while elevated pulp levels enhanced it. Augmented levels of sugar and pulp yielded a highly acceptable functional dairy beverage. The experimental values of viscosity, antioxidant activity, and overall acceptability agreed with those predicted, thus indicating suitability of the model employed. The optimized levels of ingredients for mango based dairy beverage with maximum antioxidant activity and overall acceptability were found to be milk fat $0.5 \%$, sugar $6.0 \%$, and mango pulp $30.0 \%$. 
a

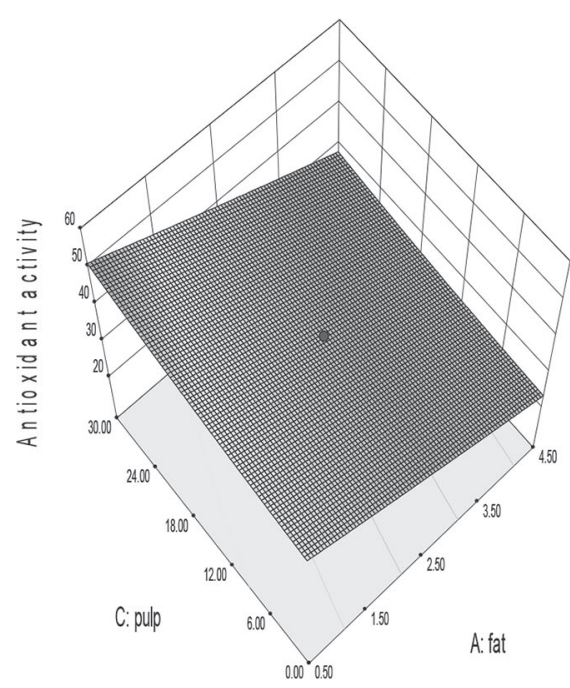

b

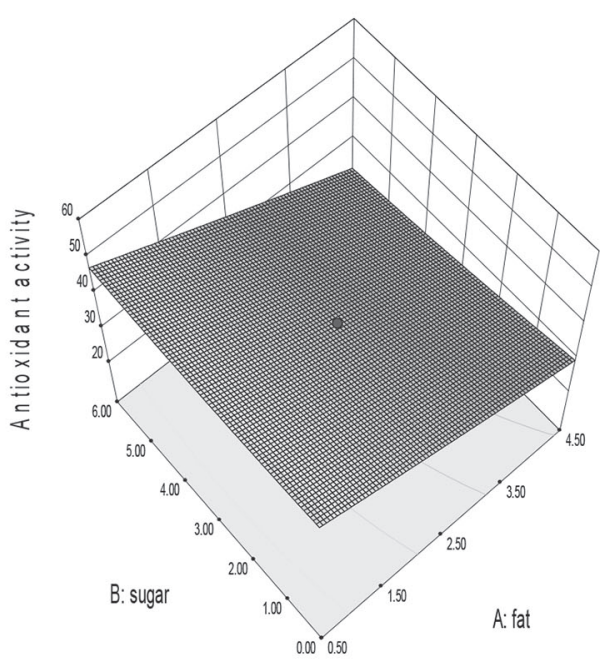

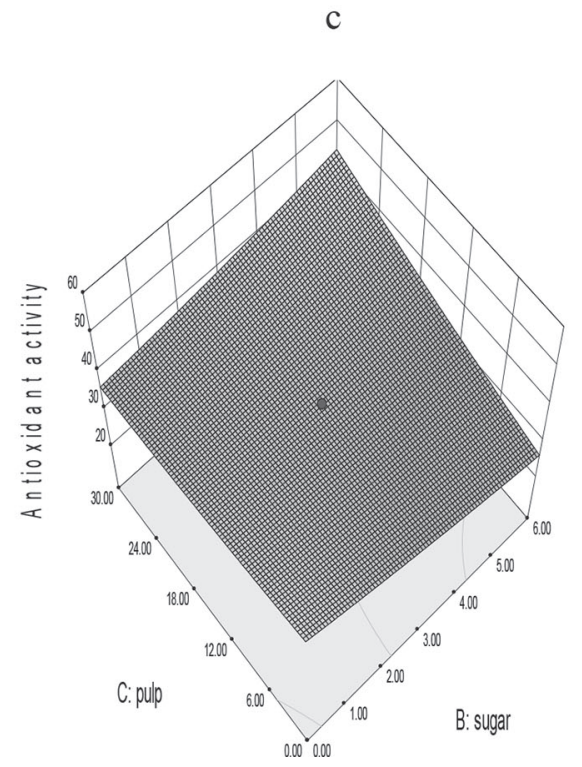

Fig 3. Three dimensional plot for antioxidant activity: a., b., c.: see Fig. 2. 


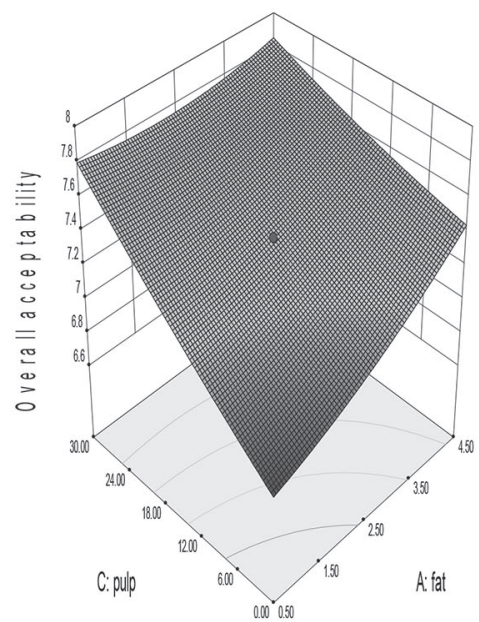

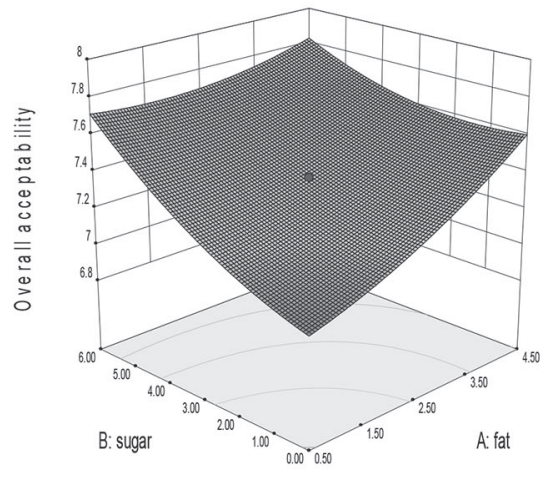

c

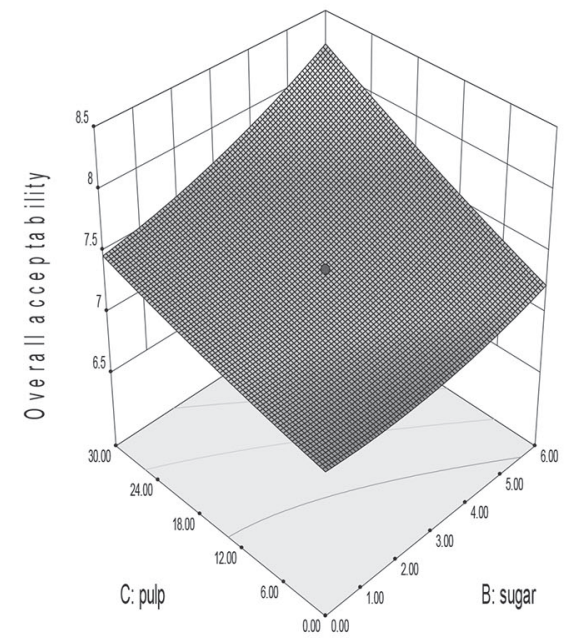

Fig 4. Three dimensional plot for overall acceptability score: a., b., c.: see Fig. 2. 


\section{References}

JACOB, R.A. (1995): The integrated antioxidant system. Nutr. Res., 15, 755-766.

Liyana-Pathirana, C.M. \& Shahidi, F. (2005): Optimization of extraction of phenolic compounds from wheat using response surface methodology. Fd Chem., 93, 47-56.

Makhlouf, H., Saksouk, M., HabiB, J. \& Chahine, R. (2011): Determination of antioxidant activity of saffron taken from the flower of Crocus sativus grown in Lebanon. Afr. J. Biotechnol., 10, 8093-8100.

Meilgaard, M., Civille, G.V. \& CARR, B.T. (Eds) (1999): Sensory evaluation techniques. CRC Press, Boca Raton, Florida, pp. 385-387.

MitTaL, S. \& Bajwa, U. (2012): Effect of fat and sugar substitution on the quality characteristics of low calorie milk drinks. J. Fd Sci. Technol., 49, 704-712.

Ozdemir, M., Ozen, B.F., Dock, L.L. \& Floros, J.D. (2008): Optimization of osmotic dehydration of diced green peppers by response surface methodology. Fd Sci. Technol., 41, 2044-2050.

Ozer, B.H. \& Kirmaci, H.A. (2009): Functional milks and dairy beverages. Int. J. Dairy Technol., 63, 1-6.

Phillips, L.G., McGiff, M.L., Barbano, D.M. \& Lawless, H.T. (1995): The influence of fat on the sensory properties, viscosity and colour of low fat milks. J Dairy Sci., 78, 1258-1266.

SHARma, A (1999): Studies on the preparation of fruits and vegetable based beverages using milk by-products and reconstituted milk. Ph. D. dissertation, Punjab Agricultural University, Ludhiana, India. 18 pages.

Smit, G. (2003): Dairy processing: Improving quality. Woodhead Publishing Limited, Cambridge, England. pp. 229-234.

Tepe, B., Sokmen, M., Akpulat, H.A. \& Sokmen, A. (2006): Screening of the antioxidant potentials of six Salvia species from Turkey. Fd Chem., 95, 200-204.

WANG, T., JónsDótTiR, R. \& ÓlafsDótTiR, G. (2009): Total phenolic compounds, radical scavenging and metal chelation of extracts from Icelandic seaweeds. Fd Chem., 116, 240-248. 